\title{
The virtual public thing: de-re-territorialisations of public space through shopping in Auckland's urban space
}

\author{
Manfredo Manfredini (First and corresponding author) \\ Ross Jenner
}

1. Public spaces in the post-consumerist city: the 'otherness' of Auckland's shopping enclaves

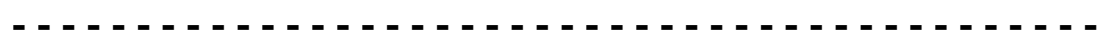

Shopping centres emerge in our cities as hegemonic social places, prodigiously magnifying the characteristics of the "worlds in miniature" that Walter Benjamin found in the Parisian arcades of the $19^{\text {th }}$ century (Benjamin 2002: 3; Böhme 2012). The recent spatial metamorphosis of that introversion of 'worlds' is at the centre of this study and is elaborated through the theories, concepts, and notions of scholars engaged with its agency in the contemporary transition of urban public space. Its exploration focuses on the transformations of the physical, social, and psychological spatialities of our post-industrial cities, examining the relationships between architecture and thenew forms of consumption emerging in the main centres of shopping, entertainment, and socialisation in the suburban space of Auckland, New Zealand. Particularly important for its discussion is the concept of "urban otherness" as proposed by Michel Foucault in the context of "heterotopia" - the place where the ordinary meets the extraordinary in conditions of simultaneity, juxtaposition, ambivalence, and dispersion (Foucault 2008: 21). This concept is adopted in the elaborations proposed by Graham Shane (2005) - who identified heterotopias as constitutive elements in the contemporary city's system of enclaves and armatures - and Dehaene and De Cauter - who reconceptualised the heterotopic device as disentangling instrument to understand the "equally treacherous and fertile condition" of the public space of our "post-civil society" (Dehaene \& De Cauter 2008: 3). Further key references framing our theoretical interpretation of this phenomenon are: the concept of "postmodern hyperspace," as developed by Fredric Jameson (1984) to describe the dramatic territorial mutations created by the disjunction of body and built environment; elaborations on the "paradox of isolation" and the critique of spatial publicness and overdetermination as central to contemporary urbanity, as proposed by David Harvey (2006), Sharon Zukin (2010), and Richard Sennett (1977); and the recent descriptions of post-consumerist society and interpretations of related emerging practices by El Hedhli, Chebat, and Sirgy (2013), Miles
(2010), and Ritzer (2013). Overall, the attempt here is to describe the idiosyncratic formal and semantic aspects that are emerging in the new 'public' places of the metropolitan centres of New Zealand's largest city. This discussion is based on the results of an empirical investigation ${ }^{1}$ of spatial elements that, given the growing digital realm, deserves particular attention to the new media. The hypothesis articulated here is that we are witnessing a profound change in the geographies of urban public space as conceived (i.e., planned, implemented, and managed), daily practiced, and steadily re-described. These changes are the result of processes of continuous deterritorialisation and reterritorialisation occurring in places with the most intensely activated spatial and digital realms - the latest generation of shopping enclaves. To validate this hypothesis, we searched for evidence of spatial representations of these enclaves that reflect the collective shift of references in the shared image of the city. Accordingly, we sought correlations between three phenomena: (1) the contribution of shopping enclaves to urban fragmentation and the consequent physical and social dis-embedding of urban territories (Giddens 1991); (2) the introversion of public space operated by shopping enclaves through a powerful set of agencies of social and cultural recontextualising (Bryman 2004: 15-56); (3) the support by shopping enclaves of emerging collective references at an urban geographic scale, one that reflects the fundamental semantic turn of the post-consumerist notion of public space.

Through an analysis of the physical contexts, social practices, and heterotopic attributes (functional, experiential and semantic) of these enclaves, this study explores how key urban public spaces are becoming increasingly introverted, externally disconnected, yet somehow integrated environmentally, socially and culturally. Such analysis examines the city of Auckland since it represents a relevant case study due to its peculiar socio-economic, cultural, and environmental conditions: it is a city topranked for liveability and mobile digital technology usage, with a social life polarised in a few centres often dominated by large-format retail, and with a very active retail sector that includes one of the world's leading shopping mall operators. The study of these places, ultimately, intends to provide evidence of the ways these centres produce new forms of public 
re-identification by being continuously re-scripted by the organisations controlling their combinatory logics (i.e., mall operators), and re-written by the public of interpreting participants (i.e., the new consumers). Methods and tools of spatial analysis are used here to assess their introversion and disconnection, as well as their unconstrainedness and hyper-connectivity granted by modern infrastructures - particularly in relation to the digital public sphere. This interrelation between the physical and the digital spatialities of the malls is also interpreted considering the profound changes in the retail sector that have recently given primacy to the emotions and experiences of citizens and consumers, not only in the conception and management of shopping enclaves but of entire cities (Richards \& Palmer 2012; Rigby 2011).

\section{The experiential turn: Experience as commodity and normalisation of spectacle}

The current post-consumerist age has been described as a global phenomenon that brings substantial changes to shopping patterns and deeply transforms people's behaviour in their broader private, public, social, cultural, and recreational lives (El Hedhli et al. 2013: 861-862; Ritzer, Dean, \& Jurgenson 2012: 381-386). One of the most important factors in its evolution is the advancement of the technological framework and, in particular, the digital infrastructure that has recently saturated our environments with mediated communication (Kang \& Cuff 2005: 109-112; Soukup 2012: 227).

Theintensification of personaldigital communications hasalsocontributed to an urban segmentation - itself initiated by transport infrastructures that has exacerbated the isolating tendency of the modern shopping mall type - what Kim Dovey has referred to as the "reversed worlds" of enclosed retail environments (Dovey 1999:123-138). The recent development of these 'heterotopic reversions' has been achieved through conflation of spaces, activities, and institutions, which has led to the production of extremely large, integrated, and mixed-use enclaves that are the prime centres for the provision of goods and services in the vast majority of developed countries (Feinberg \& Meoli 1991). The magnitude of their development has eventually reached a scale that, according to George Ritzer, is comparable to that of religious centres of traditional civilisations, qualifying them as "cathedrals of consumption" (Ritzer 1999: 7). Their growth has been accompanied by what Ash Amin and Nigel Thrift call a "performative push" (Amin \& Thrift 2002: 125) that aims at a condition permeated with performative, creative, evocative, and always variating events designed to stimulate, excite, surprise, entertain, indulge and, ultimately, generate a positive emotional state in shoppers (Arnold \& Reynolds 2003, 2009; Wakefield 2015; Wakefield \& Baker 1998). Accordingly, the retail operators of these centres strive continuously to renew sources of value for their consumers, creating scenographies that recombine the multiple layers through which locality and community are lived, interpreted, and represented. Yet these 'scenes' have an ambivalent relation to the contexts they borrow from, for they are conceived as iterable models that thinly economise resources and reinforce brand identity (Ng 2003; Schwartz \& Hochman 2014; Voyce 2006).

The evolution of the mall type, with its continual growth in size and social articulation, comes close to Victor Gruen's original ideal of the integrated civic and cultural centre. However, to the extent that this occurs, it does so in the form of heterotopias that coalesce elements of public and private, house and city, 'normalising' them all within enchanting ambiences that colour daily routines. They are ambiences with what can be thought of as the "unpolitical extraordinary" (Classen 1996: 52), feeding our contemporary anxieties of choice and attenuating the power of actuality (Crewe 2003: 353; Jansson 2002; Slater \& Tonkiss 2001: 191). Institutions that once set the civic framework of cities, such as schools, public libraries, and police stations, are now belittled, dispersed, and decentred, yet re-activated within steadily revised grand spatial narratives articulated within the closed fields and pseudo-public space of dead-end shopping places. The architectural response to this transition has meant a revision of traditional typology of malls - facilities Rem Koolhaas describes as being lost in the continuum of junkspace (Koolhaas 2001) - one that replicates with a twist what has recently been brought about in the tourism sector. In that sector, after the 1980s crisis of gaming industry resorts, the world's largest short-term accommodation establishments and major hospitality businesses shifted from being service-based providers to lifestyle and entertainment ones.

Shopping centres have followed a similar path, suburbanising the enticing, secure, and clean realm of goods deployed by $19^{\text {th }}$-century department stores (Sennett 1977: 141-149). Becoming firstly key places for social, cultural, and entertainment activities, with programmes including exhibitions, performing arts, lifestyle, and wellness (Bloch 1994: 38-39; Crawford 1992; Goss 1993: 35-29), they eventually integrated commercial spectacle with all the everyday acts, needs, and desires of public life in an age of telepresence. This latest evolution parallels the changing role of consumers, who have profoundly transformed their shopping practices and strongly increased their market power. Their empowerment has increased their autonomy, awareness, and choice mainly through new digital functionalities that include instant access to product information, price comparison, remote purchasing, and, ultimately, to on-line retail (eMarketer 2015). Consequently, as this has a direct impact on the very economic base of retail, operators have been pushed to make an additional effort in reorganising the market logic, structure, and landscape (Chung et al. 2001; Wedel \& Kamakura 2000). Their efforts were then directed to establishing synergies between the real and the digital creation of eventful shopping environments and to implementing high performing amalgamated realities with multiple hybrid platforms for the interaction between consumers and spaces, organisations, and peers. This has also comprehended the provision of services complementary to digital retail that emphasise emotional and sensorial aspects, ranging from instant purchase gratification to immersive participation in spectacular events. The mix of physical and digital agencies has supported the experiential dimension in supplanting the mere money-goods transaction as the prime form of commodity and constitutes the ideal framework for the development of the new post-consumerist acts described as "prosumption" by Ritzer (Ritzer 2013; Ritzer et al. 2012). The new type of mall operates as catalyst for all the practices in the public life of the 'prosumers' - this other to the consumer that include co-production of information (through contributions on webbased media) and events (with participation in grassroots festivals), as well as labour performances (with participation in electronic group-buying).

From the spatial perspective, such prosumption is particularly important since it is deeply involved with the collective construction and representation of new urban geographies. Prosumption can in fact be considered the response to the contemporary version of the "over-stimulation of the sensory apparatus" Georg Simmel (2002) previously attributed to the modern metropolis. Hence digitally implemented "flâneuring" (Böhme 2012) being the full exploitation of commercial spaces saturated with communications (Sacco 2011; Stikker 2013), where each sign, environment, act, and event can be captured, recorded, named, analysed, broadcast, stored, modified, and represented almost ubiquitously, with a wide range of commonly available devices. Consequently - given that a large proportion of mall visitors use smartphones ${ }^{2}-$ the development of innovative retail ecosystems with integrated digital realms is routine amongst leading operators. 'Shopping assistant' apps allow customers to easily navigate centres by selecting and finding their preferred retailers, restaurants, and events, and to receive personalised offers and discount vouchers directly via the phone. Digital kiosks with interactive mega-displays in key locations of the mall provide links to e-commerce services, 3D navigation tools, and multifarious information on offers and events (Johnson 2014; Moin 2014). Free Wi-Fi access and the malls' active deployment of multiple internet and social media platforms (including Facebook, Foursquare, Twitter, and Instagram) complete the offer to incessantly inspire, inform, and guide prosuming publics. 
This communicational framework has triggered a reconfiguration of overall mall architecture which moves beyond the allegorical pastiches of post-modernist architecture and the utilitarian clustering of anonymous built volumes (Jameson 1984: 82). New malls are increasingly complex elaborations of spatial and decorative patterning that favour ostension and originality in pursuit of memorability and imageability. Prosumers, less lost and disorientated in their consumerism, are insistently 'located' in easily intelligible spatial structures with distributed landmarks, just as they are drawn to relay their experience of these territories. At the urban scale, mall architecture is also called upon to compensate for a constitutive loss of authenticity (Zukin 1995, 2010). It creatively elaborates the tension between the introversion of commercial enclaves and required indexical memorability within the urban landscape. Using the very same means that Foucault found in the most extreme form of heterotopias, malls dissipate reality by showing themselves as hyper-real illusions, in turn resurrecting in the 'network city' something like Bruno Taut's radiant, kaleidoscopic Stadtkrone. Paradigmatic examples are Jerde's "Kanyon" in Istanbul, Hadid's Dongdaemun Design Plaza in Seoul, and Renzo Piano's 'Il Vulcano Buono' in Naples. The first centre achieves the effect of boundlessness with its curvilinear gorge/main street providing dramatic spatial sequences, the second transfigures the civic into a striking seamless field of pixellation and perforation patterns, the last introduces a new prominent topography in the periurban semirural area of the city, asserting the iconic role of the new element by figuratively mirroring the main feature of the city skyline - Vesuvius - and using the crater as central market piazza. In any case, no matter what the form or location, most of these places have been able to become in a short lapse of time hyper-active, prime urban venues for the new form of social interaction - as demonstrated by the findings on digital media usage in the newest Auckland malls discussed later in this paper.

\section{The transition from enclaves to heterotopias in Auckland's urban space}

In New Zealand the modern retail sector developed following the North American model and, accordingly, in recent times its most innovative operators have similarly embraced the experiential turn. However, the introduction here of models consolidated overseas seem to trigger the growth of peculiar interpretations that respond to idiosyncratic aspects of Auckland's context. Two contrasting sets of structural background aspects are particularly relevant: on the one hand, globally, the city stands out socially and culturally for its high quality of life and education, as results from assessments of educational attainment (OECD 2014), use of mobile digital technology, ${ }^{3}$ work-life balance, ${ }^{4}$ multiculturalism, ${ }^{5}$ and high and overall liveability show (Economist [The] 2015; Mercer 2015); on the other, the city also presents problems in the decay of the public of urban commons and the geographical polarisation of persistent social inequality (Atkinson, Salmond, \& Crampton 2014; Spoonley \& Meares 2011). Social life in suburban areas is increasingly moving to centres dominated by large-format retail clusters that are led by very active protagonists, such as Scentre Group - one of the world's leaders in the shopping mall industry (Colliers 2015; Fairgray 2013; Scentre 2015). From an economic perspective, the recent development of the retail sector has seen a consistent and steady growth in revenues, shop numbers, and total floor area, ${ }^{6}$ leading to very positive forecasts for the coming decades. ${ }^{7}$ This situation is mainly due to the combined effects of steadily increasing population ${ }^{8}$ and moderate availability of retail area per capita, which we estimated in 2014 as approximately two thirds of that in the US. The overall growth, however, is not evenly distributed throughout the sector and shows a growing divide between a positive prime and a languishing secondary group. ${ }^{9}$ Main agents of the divide are emergent 'new breeds' of retailers adept at adapting to the rapidly evolving framework (Colliers 2014: 1, 2015:1). Information concerning different attitudes of these operators is substantive in understanding the drivers of change in the conception and implementation of the new retail centres. Their differences inform the way malls vary in intensity of spatial, social, political, and cultural dis-embedment. At the urban scale, the prime group aims to dominate the physical configuration and establish key nodes in the spatial structure. Their centres therefore exaggerate spatial disjunctions, creating strong morphological and typological mismatches between mall and context (Manfredini \& Hills 2016)

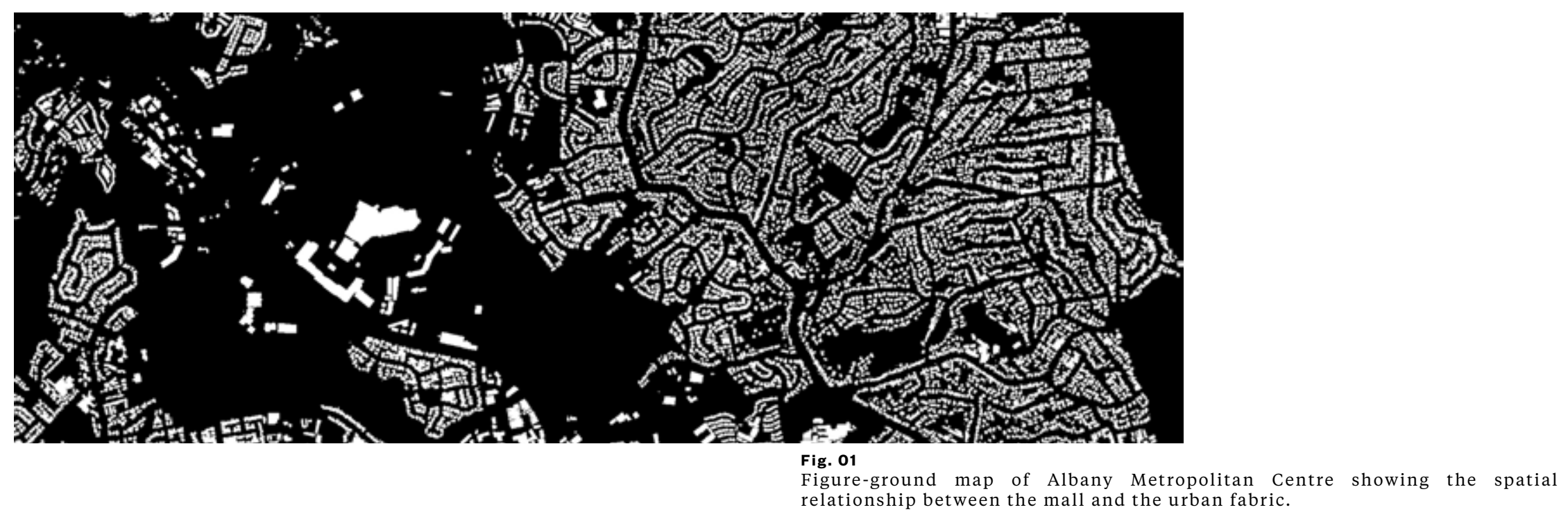


At the social and political level, the new agents strive to perfect principles of rationalisation and introduce criteria of high efficiency and control described by Ritzer (1996) as social McDonaldisation. This results in the creation of places that, concentrating key urban amenities and overpowering the role of the commons as civic agency, minimise social interaction and engagement among the consumer multitude (the largest centre, Sylvia Park, has over 12 million visitors per year). At the cultural level, the focus on maximising attraction leads to the creation of closed ambiences with strong 'experiential' transductions, often using prosaic semantic means to magnify the heterotopic experience.

Aiming to interpret how this difference relates to the emerging heterotopic sociability and memorability of these places, the study comparatively analysed the prime centres in Auckland - the group of A malls, composed of the top 10 shopping and recreational enclaves of the city. ${ }^{10}$ The study concerned eight of them - six located at the core of respective metropolitan centres (Albany, Henderson, Sylvia Park, Newmarket, Botany and Manukau) and two in secondary town centres (St Lukes and Glenfield). ${ }^{11}$ The analysis of these enclaves and their context included a collection of information on population, built environment, and digital realm. A detailed investigation aimed to evaluate the emerging socialisation component in the practiced spatialities regarded the structure and configuration of their environments. Assessment and mapping of people's practices were supported by studies on urban permeability and accessibility, physical and social infrastructures, building typology and morphology, and function of spaces. Eventually, each individual business and amenity of the selected enclaves was analysed and classified according to its basic characteristics: range of traded goods and provided services, business type (chain store/ independent shop), targeted customer group/s, brand, location, floor area, and operating times. As regards sociability, these results were then referred to four macro categories of consumer/prosumer practices: basic shopping (e.g., grocery store/grocery shopping), consumerist shopping (e.g., fashion store/fashion shopping), lifestyle consumption (e.g., movie theatre/ cultural entertainment consumption), and socialising consumption (e.g., lifestyle hospitality services/socialising consumption). Data concerning activities and practices were collected in 2014 then normalised and analysed, and results were synthetised in charts and maps. A summative map was then produced to visualise results with multilevel pie charts, where size variation comparatively reflects the relative score of each mall in the socialising consumption index

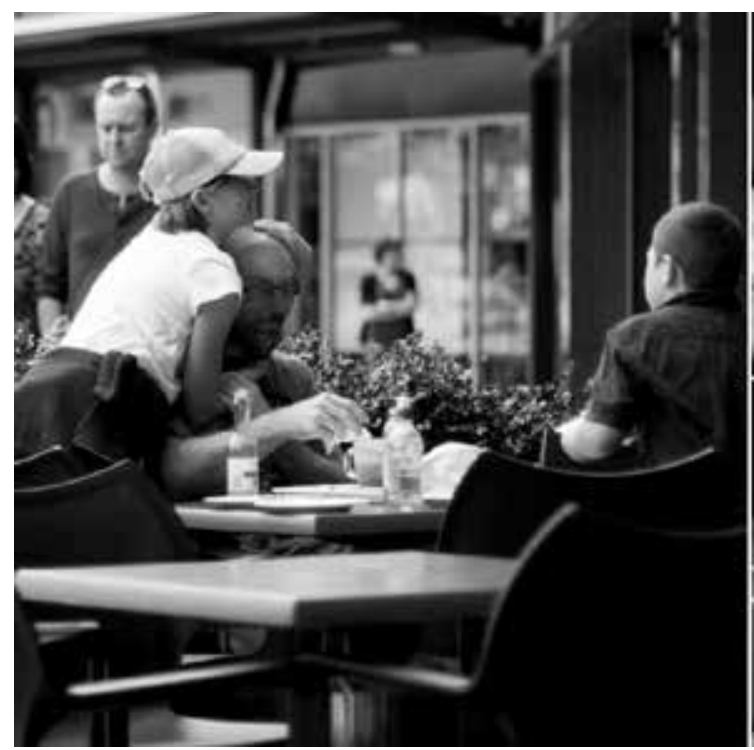

\section{Fig. 02}

Sample of images posted on social media (Instagram) in 2014 within the malls precincts and classified in different socialising consumption sub-categories. [Courtesy: Manfredo Manfredini and Jisoo Jung."]
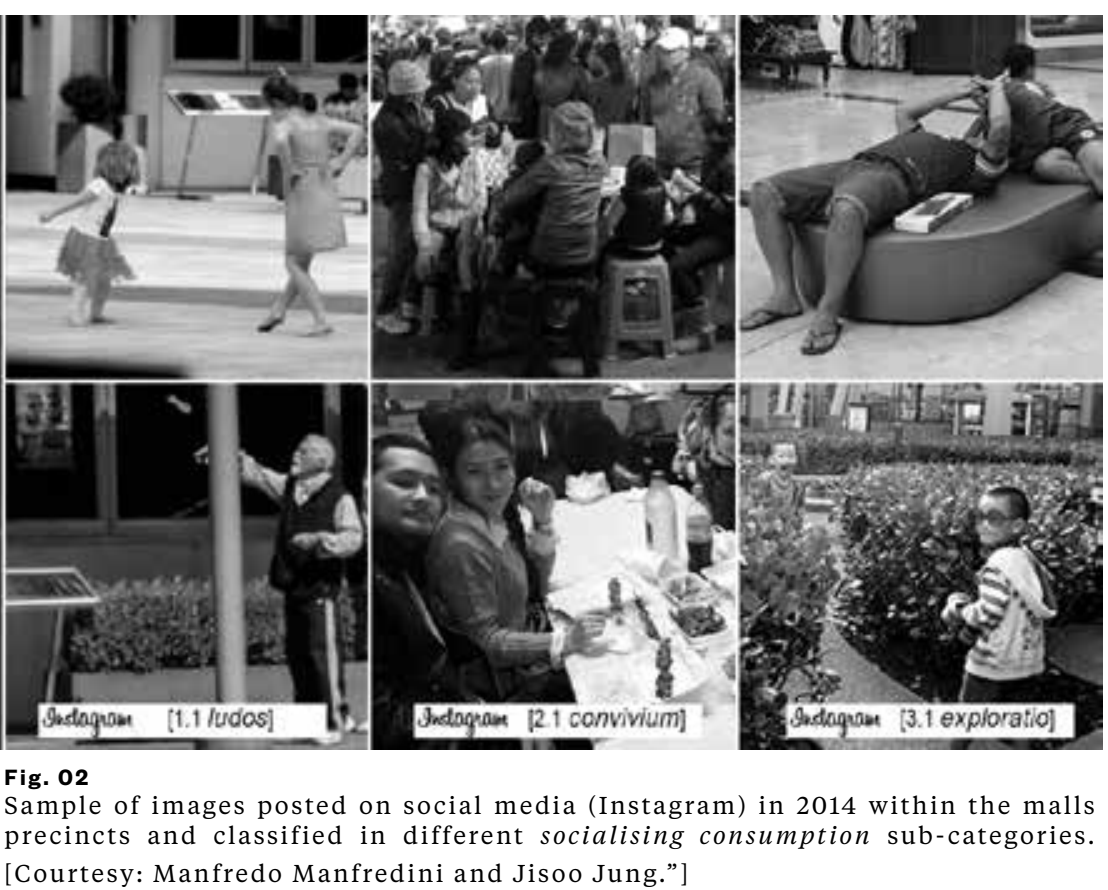

Badagran $[2.1$ convivium]
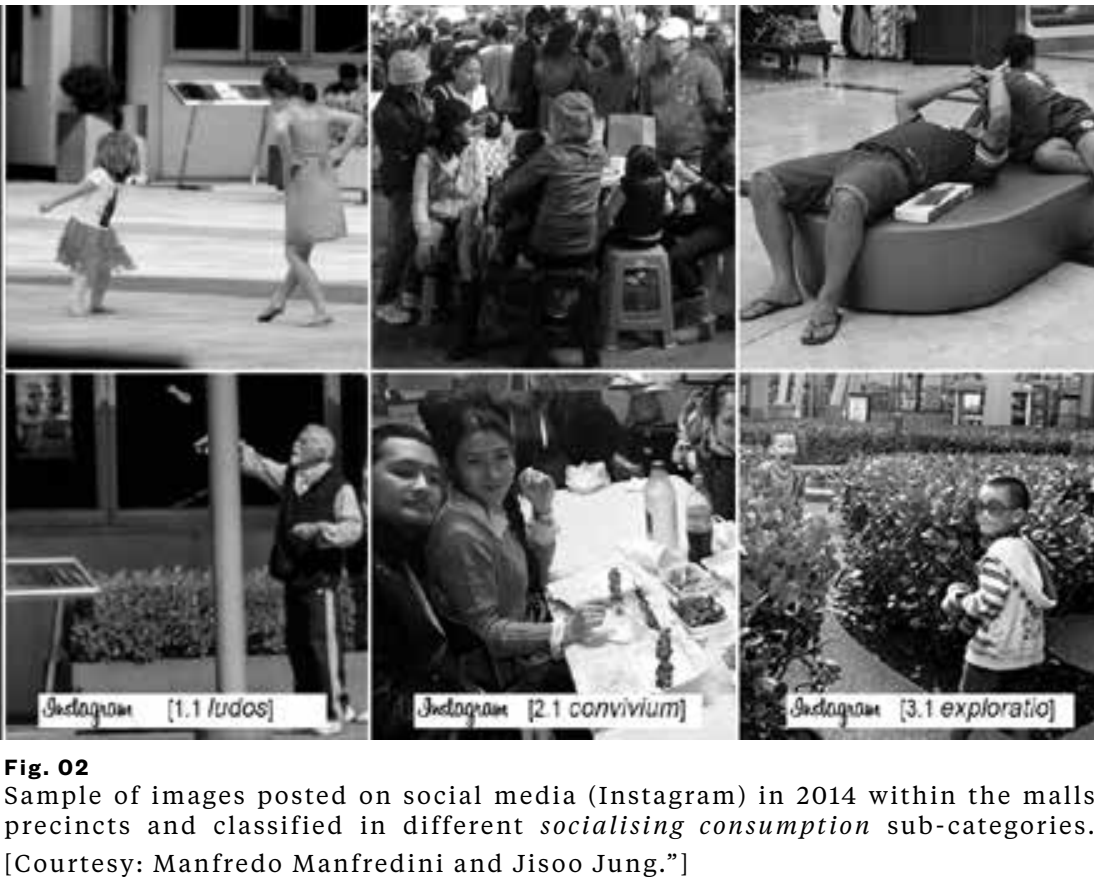

Sadraguare [3.1 expiorato]

Interstices 16 : THE URBAN THING 


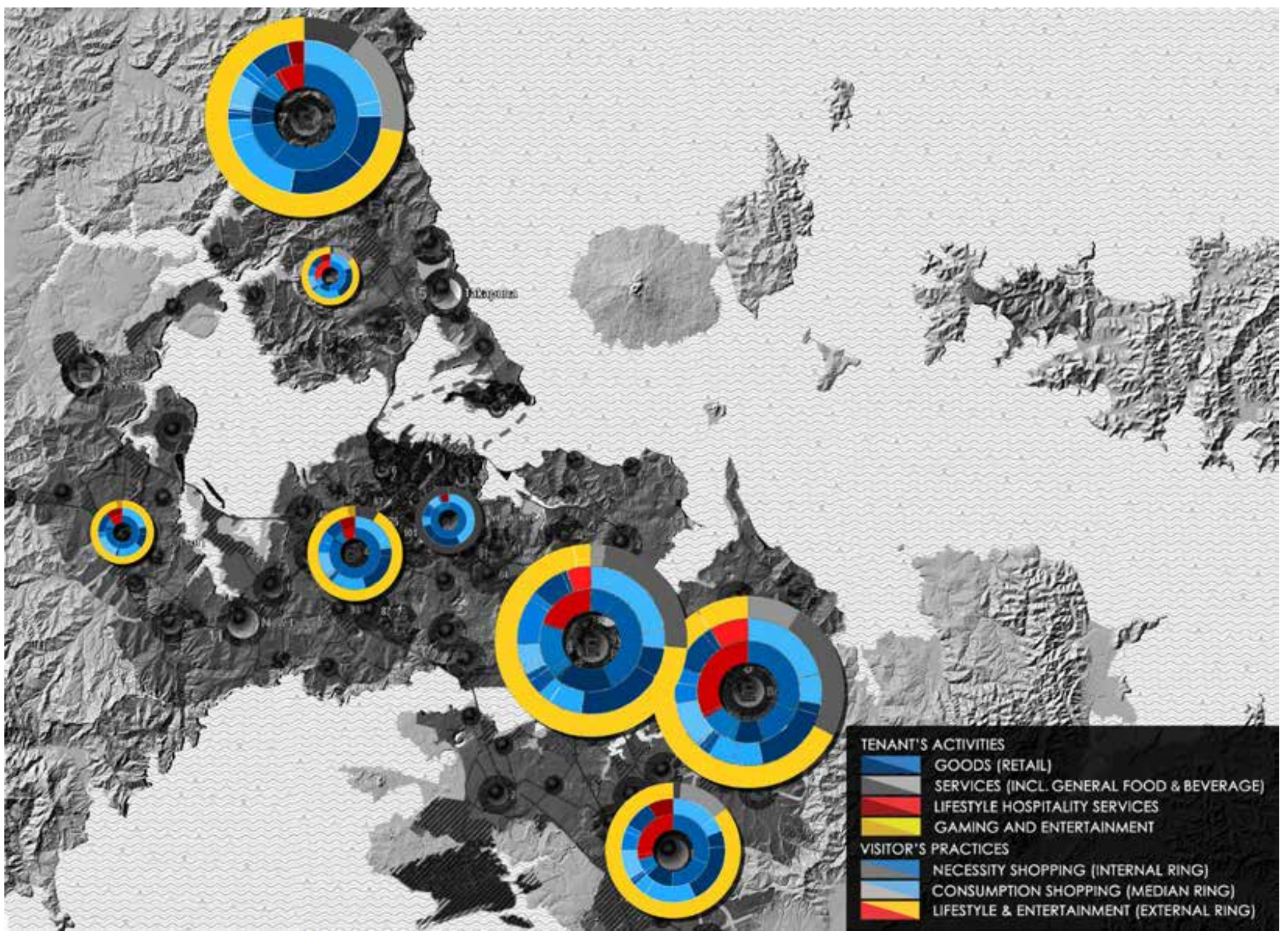

Fig. 03

Map of Auckland malls' socialising consumption index in 2014, representing the relative value of heterotopic functional integration. [Courtesy: Manfredo Manfredini and Jisoo Jung."]

As regards memorability, the results of the studies on structure and configuration of the malls were used to elaborate data spatial representation. Considering digital communication as the preeminent access to the public sphere, visual communication on social media was used as a primary source for data on spatial representation. Data were sourced using Instagram, the most popular online mobile photo and video sharing social media platform. All images posted from each mall in 2014 (from 1/01 through 31/12) were collected, using geo-tagging attributes. Data were critically analysed and images classified according to characteristics of contents, tags, and accompanying texts, identifying the character and memorability of each spatial representation. Results were then synthetised in graphs; a summative index - of spatial memorability - was created and represented in a map that visualises results with multilevel pie charts, where the score of each mall is shown by the size of each pie. The score is the relative proportion of the memorable posts (with normalised values for low, high, and medium classes). The proportion of each class of spatial images for each mall is represented by the thickness of each pie sub-ring 


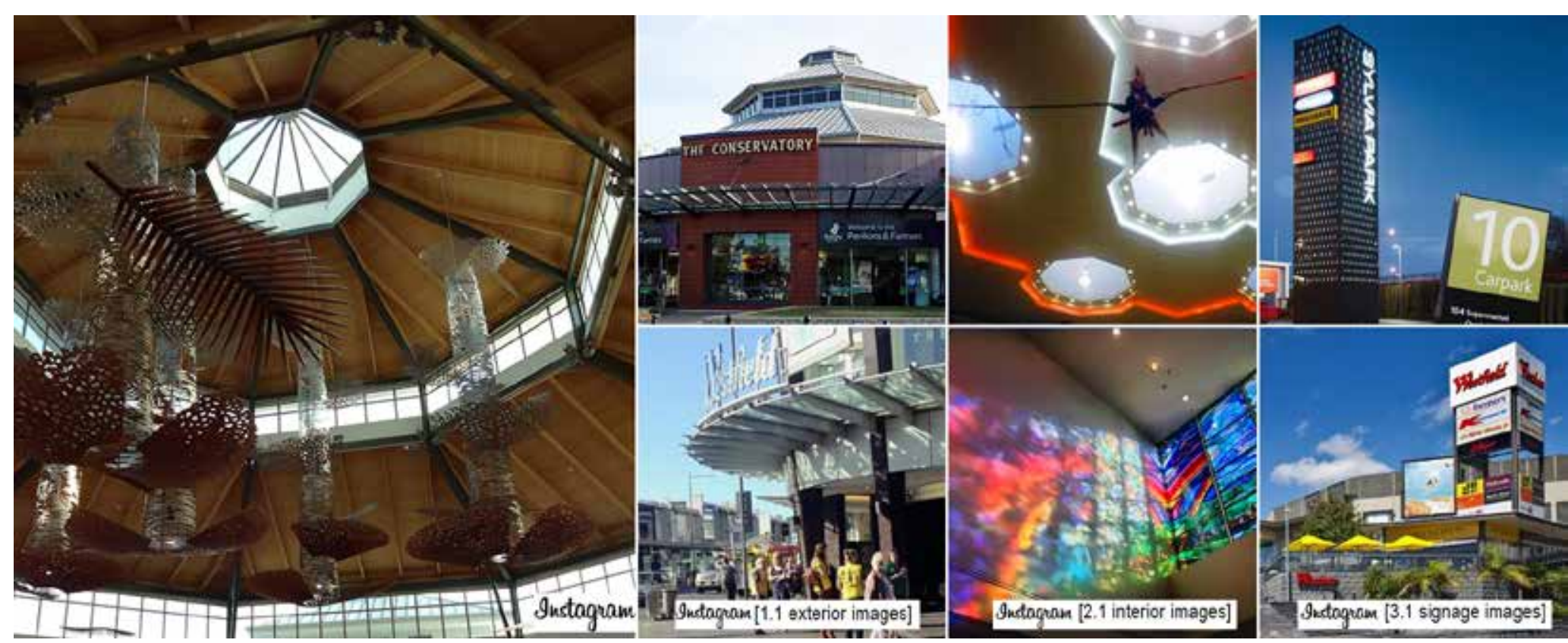

Fig. 04

Sample of images posted on social media (Instagram) in 2014 within the malls precincts and classified in different spatial memorability sub-categories. [Courtesy: Manfredo Manfredini and James Lee."]

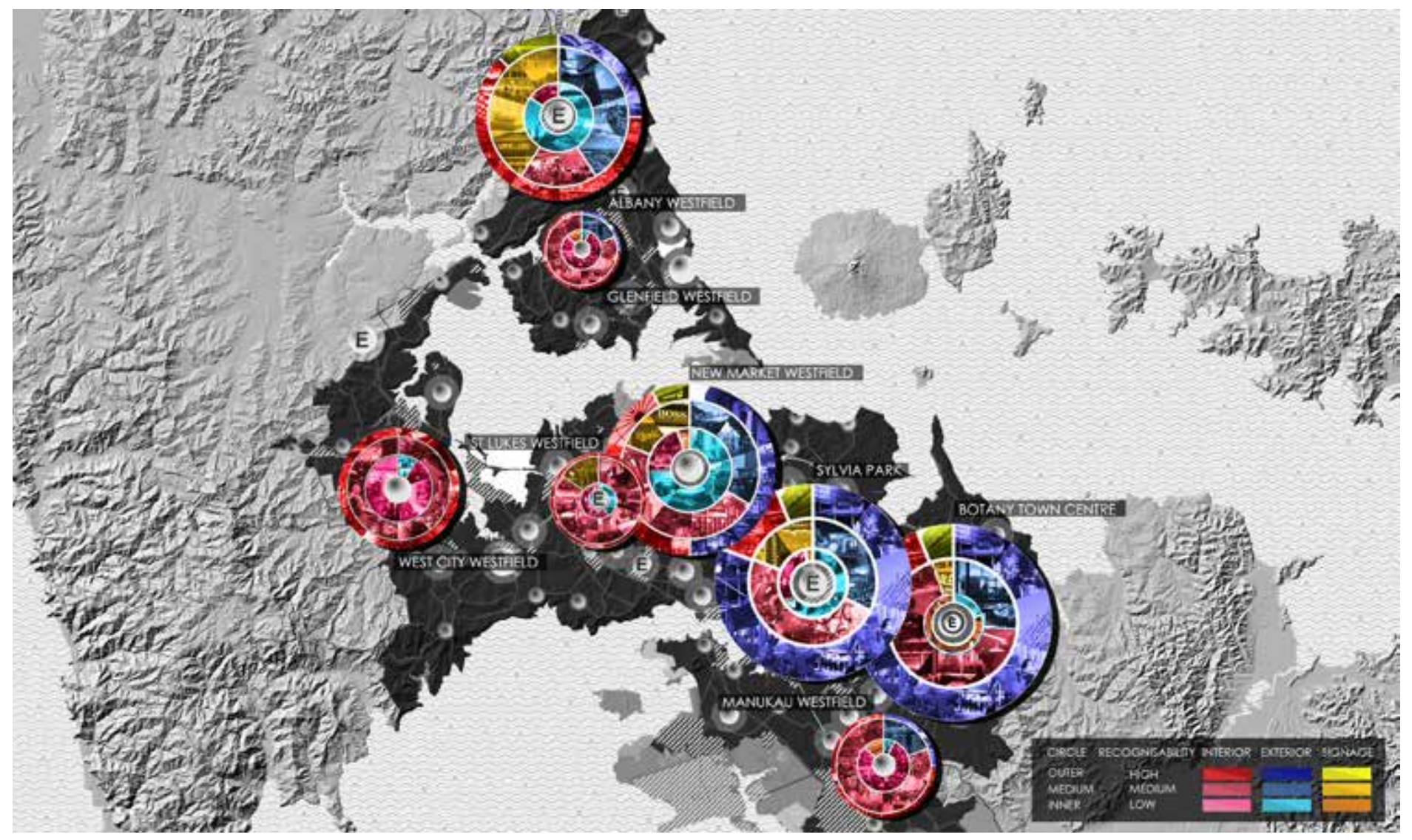

Fig. 05

Map of Auckland malls' memorability index in 2014, representing the relative value of heterotopic spatial representation. [Courtesy: Manfredo Manfredini and Jisoo Jung." 
Detailed results of this part of the investigation are available in other publications (Manfredini, Jenner, \& Litterick, 2015).

Overall, the findings showed a high consistency across the spectrum of analyses, confirming the anticipated higher heterotopic intensity of the three A+ centres - Westfield Albany, Sylvia Park, and Botany Town Centre. The higher performance of these malls stood out remarkably in both the measured indices of conceived (the physical and digital frameworks set by the operators) and practised (the consumer usage of the amenities) spatialities, with no other mall reaching comparable values. A similar result was found for the index of described spatialities (the interpretation, elaboration, and sharing of spatial images by prosumers) with only one mall scoring near the top three. These results confirmed the research hypothesis, since the data cover the three main areas of investigation. The index of conception addresses the contribution to dis-embedment, measuring urban fragmentation, community disconnection, and formal non-homogeneity. The index of spatial practices concerns the re-embedment agencies, measuring the functional integration of elements of public relational life. The index of spatial description concerns the emergence of a hyper-spatial collective urban geography and measures consistency of representation, magnitude of participation, and memorability.

\section{Auckland's enclaves of shopping, entertainment and socialisation}

To support the interpretation of the correlation between the changes in these new public spaces, the study included an investigation into the attributes of their spatial conceptions. It aimed to verify whether the malls with the highest degree of consumption and socialising, together with their memorability, have distinctive configurations and supporting management strategies. It also examined evidence of the participation of the overperforming $\mathrm{A}+$ malls in the global experiential turn. Major differences between these three malls and the others emerged from the analysis of their basic data: they are the largest and newest flagship centres of the main competing organisations and are all conceived, planned, developed, and managed to expand the shopping and entertainment realm with means that provide potential for high identification and socialisation. Their designs are indeed the only ones that include semi-open plans in the form of pedestrian lanes, squares, and plazas. They also follow an ambivalent model that favours new prosumption activities, having the highest presence of iconic features that use subtle theming strategies to strengthen their identity and memorability. Common space theming generally focuses on obvious re-embedding narratives of civic dignification - in urbanscapes of the introverted exteriors - but also of domesticity - in homely spatial pockets of fully branded interiors. The first is used to inform grand civic gestures proposed with introverted plazas and activated streets,
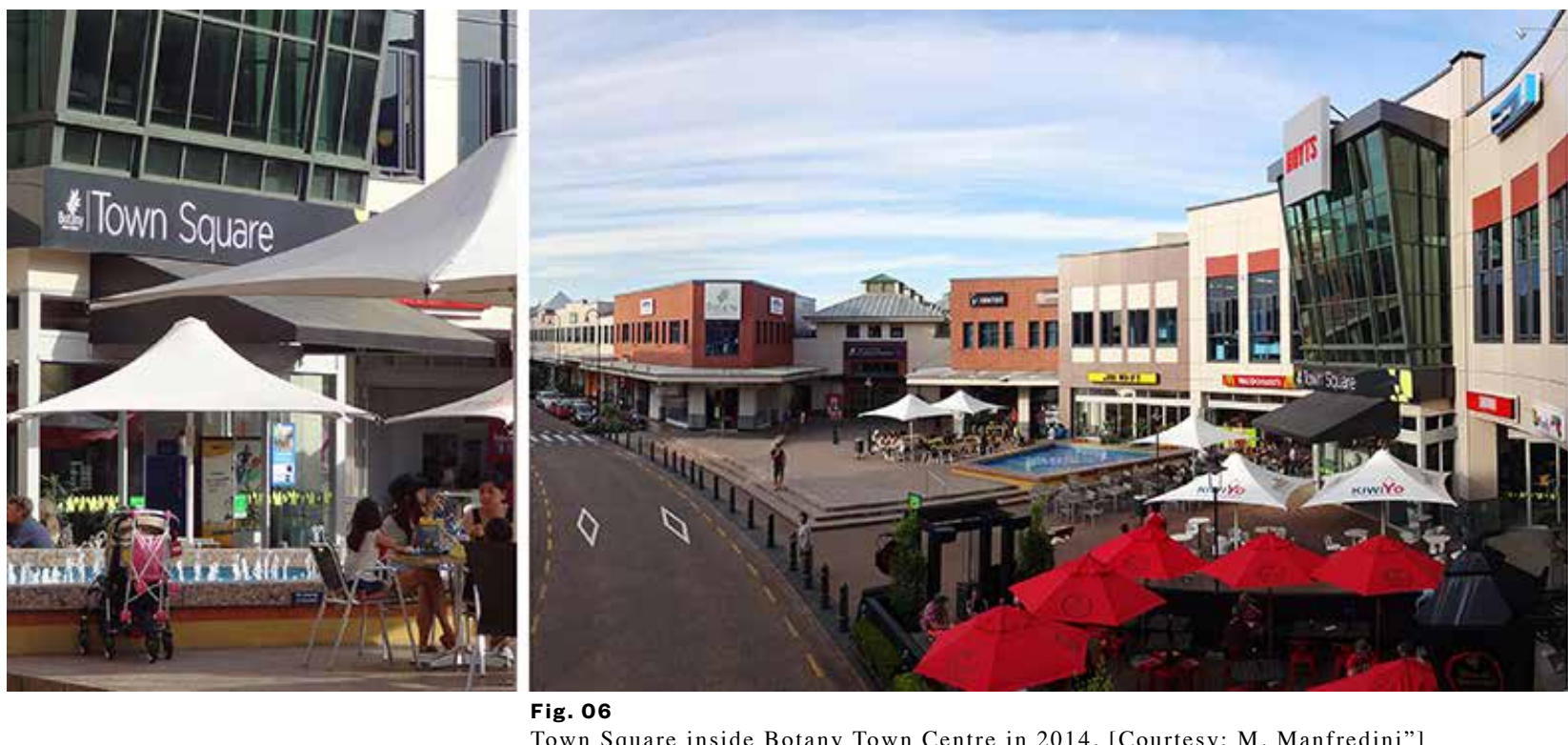
as in the stately 'patte d'oie' urban structure arranged around the selfproclaimed 'Town Square' of Botany mall

This square is an ample round open space, accessible by traffic, with a vibrant pastiche of various juxtaposed elements: a sequence of façades in different styles, continuous interspaces with porticos and overhangs, a sprinkling fountain, and a fringe of beer and cappuccino parterres. The second, conversely, is usually found in small-scale environments of pseudoprivate homely cosiness, such as the small size rest-areas interspersed throughout the aisles. Inside Sylvia Park these rest-areas help set the tone of each specific retail precinct, being either 'lordly' in high-end fashion areas (with timber floor, high backed upholstered leather armchairs, ottomans, and flower vases) or 'informal' in the young areas (with boldly coloured carpets and varieties of fancy modern chairs and amorphous seats). All these forms of augmented heterotopic introversion are presented by marketing as the ultimate social places "where lifestyle meets the latest style"12 and reflected by their inclusion at the top of the list of desirable places to visit in the city compiled by the public administration. ${ }^{13}$

The antagonistic position of these enclaves to traditional urban centres is also amplified by their separation from existing centres, being situated on key nodes of the primary road infrastructures of the low-density periphery - Sylvia Park, ${ }^{14}$ Westfield Albany, ${ }^{15}$ and Botany Town Centre, ${ }^{16}$ are respectively placed in the southern, northern, and eastern quadrants. However, the low potential for sociality is compensated by active event management that, adopting the new experiential paradigm, introduces multidimensional activities at all levels with large use of digital means. ${ }^{17}$ Thus exceptional events, such as street shows, creative performances, and semi-grassroots manifestations, guarantee a vibrant all-encompassing framework for ordinary civic life. These events are, in fact, designed to suggest a traditional urban life and instigate a certain sense of community and belonging. Examples in Botany Town Centre include programmes like the 2010 animation with performances of 20 meticulously selected buskers; the 2009-established Fun Run \& Walk, an annual running event for all; the 2015 Yank Tank Thursdays, showing American classic motor vehicles in the main street of the mall on the first Thursday of every second month; and the 2012 ceremonial start of the Silver Fern Rally, one of the major New Zealand motorsport events. Free community-based programmes are also included and range from farmers' markets to parenting groups and wellness activities, such as Sylvia Park's "Mums with Bubs" and the 'Mall Fit' walking squads. Besides those programmes, malls also host a series of grassroots events: the Asian-style night markets. These markets, which started in 2009 with weekly events at Pakuranga's mall, have since developed into an itinerant series, moving every weeknight to a different site. Their popularity, also favoured by the participation of local agencies, transforms the empty carparks from desolate and deserted tarmacs into the most vibrant gathering places on the periphery, providing an extraordinary yet ephemeral reversion of malls' disembedding effect (ANM 2015).

The condition of the three A+ enclaves is particularly relevant to the ongoing developments of several other malls and urban centres. The A+ malls set the benchmarks introducing the new experiential paradigm. Particularly affected are the remaining A malls, most of which already follow these models with important transformation phases. Four older, closed malls will shortly become semi-open, integrated, multifunctional lifestyle centres. St Lukes will double in size, with the addition of a major open air mall to create a town centre antagonistic to the nearby historical one. Newmarket's mall has a planned expansion to include a large multi-storey building and a development on public streets to add a new commercial urban precinct at the southern edge of the second largest shopping area of the city. Suburban LynnMall added a new lifestyle and entertainment precinct with a seven- theatre cinema complex and a range of cafés and restaurants in 2015 to reaffirm its primary role in the recently redeveloped New Lynn town centre (Gibson 2015a). Lastly, the Downtown Shopping Centre, located at the very centre of the $\mathrm{CBD}$, will be completely redeveloped with an expansion onto a recently alienated public square to "kick-off the creation of a world-class downtown area" that will include new open public space and transport facilities (Council 2014: 15; Council 2015).

The above findings reveal a consistency between the results of the qualitative and quantitative analyses on the heterotopic aspects of shopping enclosures: the coherence between the high intensity achieved by the three significantly outperforming centres as regards practices of socialisation and memorability, and higher support by the thorough strategies and actions of developers and operators. This further confirms our hypothesis that the production of spaces, both highly deterritorialising and reterritorialising, is having strong and tangible effects to the transformation of the urban geography. This is a distinctive effect of the extremely illusionary and compensatory spatial function provided by the new pseudo-public places as a response to their constitutive contradiction of being formally instituted as civic poles but substantially disjoined from their urban contexts. The epitome of this condition was found in the central places of the consumers' relational life in these enclaves. As the study of their spatial attributes is ultimately confirmed, architecture and urban design have a high relevance in shaping the physical structures, which means in these spaces contributing to virtualising normality in the "(atopic) network space" of our city (Dehaene \& De Cauter 2008: 5). Therefore, given the capacity of the new heterotopic enclaves to transform the spaces of our daily life, we hope that the results of this research stimulate a fundamental re-thinking of the way architects conceive and plan them. An increased effort to understand this concretisation of spatial aporia accompanied by a social, cultural, and design responsibility is demanded: the enactment of heterotopia par excellence - a place without a place "that is self-enclosed and at the same time is given over to the infinity" (Foucault 2008: 22) and comprises the exceptional dimension of dream, imagination, and pleasure. 


\section{End notes}

This study is framed in the research project titled "Auckland' Public spaces: Retail landscapes and social life in the urban centres" developed at University of Auckland since 2014.

2 Westfield estimates that $75 \%$ of their clients use internet features, while $62 \%$ Facebook and Twitter (Westfield Labs, 2015).

3 New Zealanders' early adoption of new technology is reflected in the high use of smartphones, that in 2014 concern almost $60 \%$ of the population (Nielsen, 2015) According to the New Zealand Government "Guide to living \& working in New Zealand," the country's "the work-life balance is just right" (New Zealand Immigration, 2015). 52013 census data showed the increasing cultural diversity of Auckland's population, with the European progressively declining to $50 \%$ of the total (Social and Economic Research, 2014) A recent Colliers International report highlighted how, with the continuous growth of the real GDP of the retail sector, negative only in 2009 , across New Zealand its development activity is rising in all its forms (Colliers, 2014, 2015).

7 A study of the Research, Investigations and Monitoring Unit of the Auckland Council estimated that in 2012 the City's almost 4 million m 2 of retail floor space offered a share of $7.79 \mathrm{~m}^{2}$ per household, and predicted a growth by 35 per cent between 2012 and 2031, with large format retail, already accounting fo over one-third of the total, taking over half of retail floor space growth (Fairgray, 2013). The positive trend is also confirmed by a study by Colliers International that points out the success of high profile premises, with vacant space in regional centres at just $0.3 \%$ (Colliers, 2014; Ltd, 2008). For the next 30 years Statistics New Zealand has projected a medium (he plan for its future development on the high population growth projection of one million people (Council, 2012). pace (Colliers, 2015; Gibson, 2015c)

10 This classification of centres is a generic distinction widely used in the sector to distinguish structures that respectively have the best construction and location (A), high quality of one of the two above (B), and everything else (C).

11 This study considers 8 of the 10 malls commonly identified as regional retail centres (the $C B D$ and New Lynn are excluded as currently under relevant expansion and redevelopment). They are located in the administrative areas of the pre 2011 amalgamation cities of North Shore (Albany and Glenfield), Waitakere (Westcity) Auckland City (St. Lukes, Newmarket and Sylvia Park) and Manukau (Manukau and Botany). These malls are rather evenly distributed throughout the urban area, with relative distance ranging from ca. 4 to $7.5 \mathrm{~km}$, comprised in an interval of total leasable area ranging from ca, 30,000 to 70,000 $\mathrm{m}^{2}$, and comprehending a number of shops ranging from ca. 110 to 200 . This large scale statement is located on the freestanding gate at the main carpark entrance to the St Lukes mall.
The lived emotional and aesthetic component of a mall visit is recognised by the ATEED, the economic Council-controlled growth agency for the Auckland region, with the introduction of four mall destinations (Sylvia Park, Botany Town Centre, the Westfield centres, and the DressSmart fashion outlet) in the list of desirable place to visit in Auckland, under the category "Experience" (http://www.aucklandnz.com/things-to-do). Moreover, Botany Town Centre is promote as "major attraction" for the larger Howick Local Board area (Council \& Board).

14 2006, owned and managed by Kiwi Property, is the largest mall in the country, with approximately $70,000 \mathrm{~m}^{2}$ of leasable area, 190 stores and 4000 car parking spaces. It is developed on a single axis, of more than 600 meters in length, interrupted by an open courtyard and a highway viaduct. It is mainly on one level, with some parts on two, hosting three main anchor tenants and a cinema.

15

Westfield Albany, designed by Woodhams, Meikle and Zhan, Westfield Design and JCY Architects, was entirely opened 2008. It is owned (51\%) and managed by Scentre Group, and is the largest mall in the North Shore with approximately $53,000 \mathrm{~m}^{2}$ of leasable area, 145 stores and 2300 car parking spaces. It is developed on three axes converging at the main entrance, leading to the three main anchor tenants and a cinema. It is mainly on one level, with some parts on two and has an open plaza facing the Albany Lakes Civic Park.

Botany town centre, designed by Altoon + Porter and Hames Sharley, opened in 2001, is the largest mall in East Auckland. It is owned by PSP Investments, Canada, and managed by AMP Capital. It has approximately 200 shops and 2400 car parking spaces. It is developed around a central open-air square and has two main anchor tenants and a cinema. It is mainly on one level, with some parts on two.

17 17 The engagement with the digital realm is reflected by the number of activated internet services, posts, and followers on social media. However, also between them there is a relevant difference, as results from their reaching values of followers of the most popular platform, Facebook, ranging from Sylvia Park's 16.000 to Botany Town Centre's 6,337, as of August 2015 (Westfield malls figures are very difficult to estimate they are all merged in a single account). 


\section{References}

Amin, A., \& Thrift, N. (2002). Cities: Reimagining the urban. Cambridge, England: Polity.

ANM. (2015). Auckland Night Markets : Food, fashion, family-fun. Retrieved 18.06.2015 from http://www.aucklandnightmarket.co.nz/locations/

Arnold, M. J., \& Reynolds, K. E. (2003). Hedonic shopping motivations. Journal of Retailing, 79(2), 77-95.

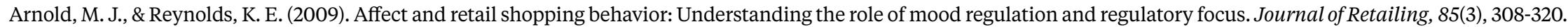

Atkinson, J., Salmond, C., \& Crampton, P. (2014). NZDep2013 Index of deprivation. New Zealand, Ministry of Health

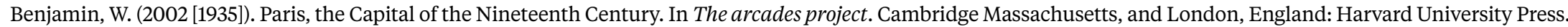

Bloch, P. H., Ridgway, N. M., \& Dawson, S. A. (1994). The shopping mall as consumer habitat. Journal of Retailing, 70(1), $23-42$.

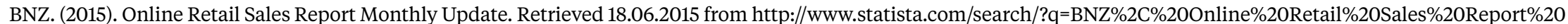
Monthly\%20Update\%2C\%2025\%20June\%202015\%2C

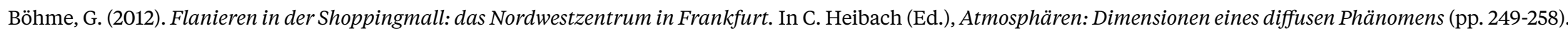
Munich: Fink.

Bryman, A. (2004). The Disneyization of society. London, England: Sage.

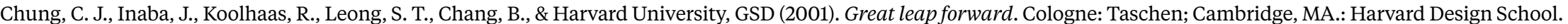

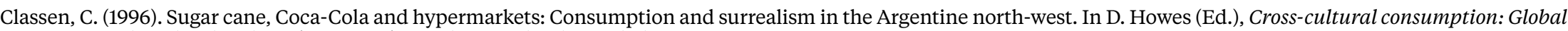
markets, local realities (pp. 20-38). London, England: Routledge.

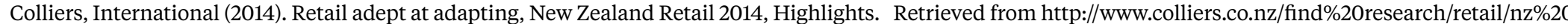
retail\%20report\%202014/

Colliers, International (2015). New Zealand retail 2015, retail reality check. Auckland: Collers International.

Council, Auckland (2012). The Auckland plan. Retrieved from http://www.aucklandcouncil.govt.nz/EN/planspoliciesprojects/plansstrategies/theaucklandplan/ Documents/aucklandplanenglish.pdf

Council, Auckland (2014). Introduction to the downtown framework. Auckland: Auckland Council. 
Council, Auckland (2015). Mayor hails historic City Rail Link development, Retrieved from http://www.aucklandcouncil.govt.nz/EN/newseventsculture/ OurAuckland/mediareleases/Pages/mayorhailshistoriccityraillinkdevelopment.aspx

Council, Auckland, ATEED. (2015). Auckland, Retrieved from (http://www.aucklandnz.com/things-to-do).

Council, Auckland, \& Howick Local Board (2015). Pakuranga town centre masterplan. Auckland: Auckland Council.

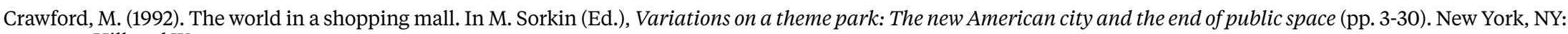
Hill and Wang.

Crewe, L. (2003). Geographies of retailing and consumption: Markets in motion. Progress in Human Geography, 27(3), 352-362.

Crossley, J. (2009). Westfield wins council approval for Newmarket expansion. National Business Review (Tuesday June 16)

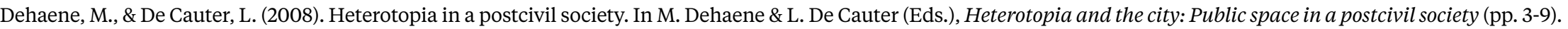
New York, NY: Routledge.

Dovey, K. (1999). Framing places: Mediating power in built form. New York, NY: Routledge.

Economist [The] (2015). The world's most 'liveable' cities. Retrieved from http://www.economist.com/blogs/graphicdetail/2015/08/daily-chart-5

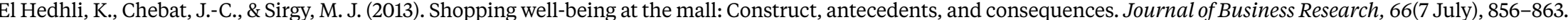
S.n. (2015). Worldwide retail ecommerce sales: eMarketer's estimates and forecast, 2013-2018, eMarketer.

Fairgray, S. (2013). Auckland retail economic evidence base. Retrieved from www.aucklandcouncil.govt.nz/.../tr2013046aucklandretaileconomicevidencebase

Feinberg, R. A., \& Meoli, J. (1991). A brief history of the mall. Advances in Consumer Research, 18(1), 426-427.

Foucault, M. (2008). Of other spaces (1967). In M. Dehaene \& L. De Cauter (Eds.), Heterotopia and the city (pp. 13-29). New York, NY: Routledge.

Gibson, A. (2014). Singapore buys into NZ malls, NZ Herald. Retrieved from http://www.nzherald.co.nz/business/news/article.cfm?c_id=3\&objectid=11383778

Gibson, A. (2015a). Auckland’s Lynn Mall expansion gets under way, New Zealand Herald. Retrieved from http://www.nzherald.co.nz/business/news/article.cfm?c id=3\&objectid $=11383778$

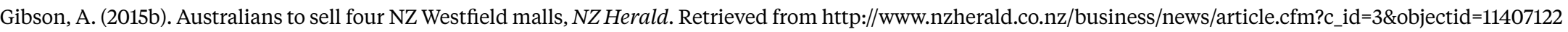

Gibson, A. (2015c). The big read: Mega shopping malls get a roll on, New Zealand Herald. Retrieved from http://www.nzherald.co.nz/business/news/article.cfm?c id=3\&objectid=11529022

Giddens, A. (1991). Modernity and self-identity: Self and society in the late modern age: Stanford, CA: Stanford University Press

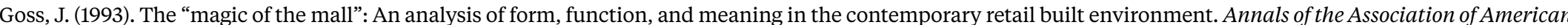
Geographers, 83(1), 18-47.

Harvey, D. (2006). The political economy of public space. In N. Smith \& S. Low (Eds.), The politics of public space (pp. 17-34). New York, NY: Routledge.

Jameson, F. (1984). Postmodernism, or the cultural logic of late capitalism. New left review, 146 (July/August ), 53-92.

Jansson, A. (2002). The mediatisation of consumption. Journal of Consumer Culture, 2(1), 5-31.

Johnson, L. (2014). This innovation lab is designing the mall of the future food court delivery and shoppable screens. Adweek, November 20.

Kang, J., \& Cuff, D. (2005). Pervasive computing: embedding the public sphere. Wash. \& Lee L. Rev., 62, 93-146.

Kiwi Property. (2015a). Mall fit. Retrieved from http://www.sylviapark.org/mall-fit

Kiwi Property. (2015b). Mums with bubs. Retrieved from http://www.sylviapark.org/mums-bubs

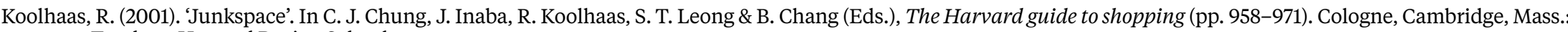
Taschen, Harvard Design School.

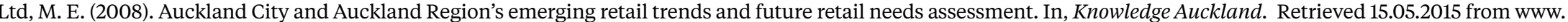
itsmybackyard.co.nz/resources/research-retailresearchreport.pdf

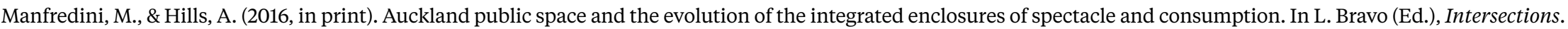
Florence: The University of Florence Press.

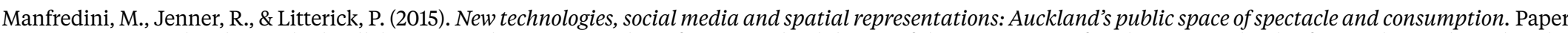
presented at the Applied Collaboration, 8th International Conference and Exhibition of the Association of Architecture Schools of Australasia, Christchurch. 
Mercer. (2015). 2015 Quality of living survey. Retrieved from http://www.uk.mercer.com/newsroom/2015-quality-of-living-survey.html

Miles, S. (2010). Spaces for consumption: Pleasure and placelessness in the post-industrial city. Los Angeles, CA: SAGE Publications.

Moin, D. (2014). Digital kiosks fuse in-store and online shopping. WWD, Retail news, marketing and consumer behavior.

New Zealand Immigration. (2015). Balanced lifestyle. Retrieved from https://www.newzealandnow.govt.nz/why-choose-nz/balanced-lifestyle

Ng, C. F. (2003). Satisfying shoppers' psychological needs: from public market to cybermall. Journal of Environmental Psychology, 23 (4), $439-455$.

Nielsen (2015). New Zealand multi-screen report. Nielsen.

NZH, New Zealand Herald (2010). St Lukes mall expansion approved, New Zealand Herald. Retrieved from http://www.nzherald.co.nz/business/news/article.cfm?c_ id=3\&objectid $=10688175$

OECD (2014). Education at a glance 2014: OECD Indicators. OECD.

Richards, G., \& Palmer, R. (2012). Eventful cities: New York, NY: Routledge.

Rigby, D. (2011). The future of shopping. Harvard Business Review, 89(12), 65-76.

Ritzer, G. (1996). The Mcdonaldization thesis: Is expansion inevitable? International Sociology, 11, 291-308.

Ritzer, G. (1999). Enchanting a disenchanted world: Revolutionizing the means of consumption. London, England: Pine Forge Press.

Ritzer, G. (2013). Prosumption: Evolution, revolution, or eternal return of the same? Journal of Consumer Culture, 14(1), 3-24.

Ritzer, G., Dean, P., \& Jurgenson, N. (2012). The coming of age of the prosumer. American Behavioral Scientist, 56(4), 379-398.

Sacco, P. L. (2011). Culture 3.0: A new perspective for the EU 2014-2020 structural funds programming.

Scentre Group (2015). 2014 Full year results. Retrieved from http://2amoob1qhep81coj5547cdmv.wpengine.netdna-cdn.com/wp-content/uploads/2015/02/SCGresults-presentation-FINAL.pdf

Schwartz, R., \& Hochman, N. (2014). The Social media life of public spaces: Reading places through the lens of geo-tagged data. In R. Wilken \& G. Goggin (Eds.), Locative media. New York, NY: Routledge.

Sennett, R. (1977). The fall of the public man. New York, NY: Knopf.

Shane, D. G. (2005). Recombinant urbanism: Conceptual modeling in architecture, urban design, and city theory. Chichester, England: Wiley.

Simmel, G. (2002 [1903]). The metropolis and mental life. In G. B., S. Watson (Ed.), The Blackwell city reader. Oxford, England and Malden, MA: Wiley-Blackwell.

Slater, D., \& Tonkiss, F. (2001). Market society. Cambridge, England: Polity Press.

Social and Economic Research, I. a. M. U., Auckland Council. (2014). Auckland profile - initial results from the 2013 census. Auckland: Auckland Council.

Soukup, C. (2012). The postmodern ethnographic flaneur and the study of hyper-mediated everyday life. Journal of Contemporary Ethnography, 42(2), $226-254$.

Spoonley, P., \& Meares, C. L. (2011). Laissez-faire multiculturalism and relational embeddedness: Ethnic precincts in Auckland. Cosmopolitan Civil Societies: An Interdisciplinary Journal, 3(1), 42-64.

Stikker, M. (2013). Public domain 4.0. In D. Hemment, Thompson, B., de Vicente, J.L., Cooper, R (Eds), Digital public space. Manchester, England: Future Everything. Voyce, M. (2006). Shopping malls in Australia: The end of public space and the rise of 'consumerist citizenship'? Journal of sociology, 42(3), $269-286$.

Wakefield, C. (2015). Global cities retail-unitedstates. Retrieved from http://cwglobalretailguide.com/unitedstates/

Wakefield, K. L., \& Baker, J. (1998). Excitement at the mall: Determinants and effects on shopping response. Journal of Retailing, 74(4), 515-539.

Wedel, M., \& Kamakura, W. A. (2000). Market segmentation: Conceptual methodological foundations. Boston, MA: Kluwer Academic.

Westfield Labs. (2015). Converging digital shoppers with physical retail. Retrieved from http://www.westfieldlabs.com

Zukin, S. (1995). The cultures of cities. Oxford, England: Wiley-Blackwell.

Zukin, S. (2010). Naked city: The death and life of authentic urban places. Oxford, England; New York,NY: Oxford University Press. 